\title{
Ictal catatonia as a manifestation of nonconvulsive status epilepticus
}

\author{
JAIME LIM, PRATAP YAGNIK, PAUL SCHRAEDER, STEVE WHEELER \\ From the Medical College of Pennsylvania and Philadelphia Veterans Administration Medical Center, \\ Philadelphia, USA
}

SUMMARY Three patients with EEG documented ictal catatonia, a nonconvulsive status epilepticus, who responded dramatically to intravenous phenytoin are described. The EEG showed continuous bilateral pseudoperiodic sharp waves and spike discharges in one patient, spike and wave complexes were seen prominently in the right fronto-central region in another, and the EEG of the third patient showed periodic lateralising epileptiform discharges during the catatonic state. We postulate that such catatonia was due to involvement of the limbic system by seizure activity.

Kahlbaum ${ }^{1}$ first described a syndrome consisting of catalepsy and waxy flexibility, mutism, muscle rigidity, psychotic negativism, stereotypies and verbigeration. These symptoms are associated with conditions such as schizophrenia, affective disorders, and a variety of metabolic derangements and structural disorders of the brain. ${ }^{2}$ Adequately documented catatonia with concurrent epileptic discharges on the electroencephalogram (EEG) has been described only rarely. ${ }^{3-5}$ We report three cases of nonconvulsive status epilepticus, confirmed by EEG, manifested by catatonia which responded to intravenous phenytoin.

\section{Case reports}

Case 1 A 55-year-old black male had a long history of chronic psychosis and was treated with thioridazine. He presented to another hospital with four generalised tonic/clonic seizures which were controlled with intravenous diazepam. On examination at the Philadelphia VA Medical Center the patient appeared awake but had a fixed and glassy-eyed stare. His eyes were in the midline. His face was immobile. He did not recognise his environment. Occasionally, upon repeated questioning, the patient would utter his name. Cranial nerve function was intact. Muscle tone was increased with no focal weakness. However, he exhibited waxy flexibility, maintaining the extremities indefinite in any passively placed bizarre posture. The EEG on the day of admission showed continuous bilateral pseudoperiodic sharp waves and spike discharges (fig lA).

Address for reprint requests: Pratap Yagnik, MD, Department of Neurology, Philadelphia VA Medical Center, University and Woodland, Philadelphia, PA 19104, USA.

Received 10 June 1985 and in revised form 28 October 1985. Accepted 2 November 1985
After 1 gram of phenytoin had been given intravenously the catatonia improved. The next day he was alert, oriented, and appropriate. A second EEG, (fig 1B), a CT scan, CSF studies and routine laboratory studies were normal.

Case 2 A 67-year-old man presented with a two week history of confusion. He would talk nonsense, not recognise his brother, and on occasion, urinated on his bed. When questioned, he gave the address of the residence where he lived 10 years ago, and he expressed paranoid ideation. There was a history of one seizure 15 years ago secondary to head trauma from an automobile accident. On examination the patient appeared depressed and sat quietly in a chair, with no spontaneous speech or movement. He responded to questions with few words and manifested frequent echolalia and perseveration. At one point the patient started crying loudly and shouted, "I don't know" to most of the questions asked. He subsequently exhibited labile affect, with extremes of depression, bursts of crying, severe agitation and combativeness. The patient was confused. On the third hospital day the patient suddenly became catatonic. His mouth and eyes were opened widely with dilated reactive pupils. He held his arms and legs rigidly in the air and would maintain his extremities in any bizarre position indefinitely. The psychiatric consultant diagnosed severe psychotic depression and recommended electroconvulsive therapy (ECT). An EEG showed continuous spike and wave complexes originating in the right fronto-central region with some spread to the left hemisphere. After 1 gram of phenytoin was adminstered intravenously the catatonic postures resolved and the patient awaked. By the next day, he was alert and oriented with appropriate speech and affect. Neurological examination was normal. A repeat EEG showed mild diffuse slowing. A CT scan of the head showed minimal diffuse cerebral atrophy. The CSF was normal.

Case 3 A 59-year-old male admitted with frequent episodes of confusion for three weeks. During these episodes he was observed to stare blankly with a decrease in verbal output and physical activity. One year prior to the admission he 


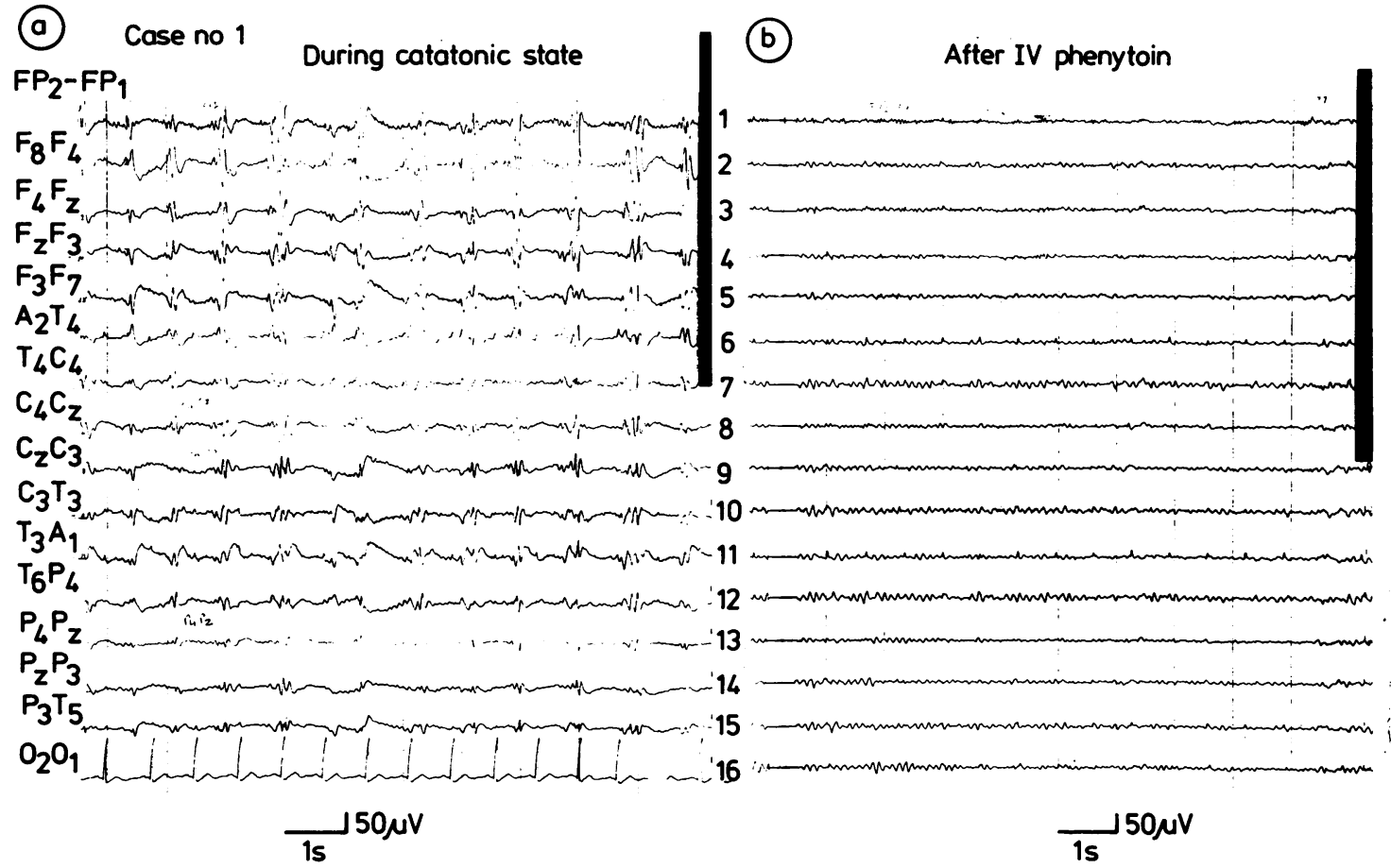

Fig 1 (a) EEG of case 1 showing bilateral pseudoperiodic sharp waves and spike discharges during catatonia. (b) Repeat $E E G$ on next day when the patient had improved showed no abnormalities.

(a) Case no 3

$F_{2} F_{4}$
$F_{4} C_{4}$
$C_{4} P_{4}$
$P_{4} O_{2}$

$F P_{1} F_{3}$

$\mathrm{F}_{3} \mathrm{C}_{3}$

$\mathrm{C}_{3} \mathrm{P}_{3}$

$\mathrm{P}_{3} \mathrm{O}_{1}$

$\mathrm{F}_{8} \mathrm{~T}_{4}$

$T_{4} T_{6}$

$\mathrm{T}_{6} \mathrm{O}_{2}$

$\mathrm{F}_{7} \mathrm{~T}_{3}$

$T_{3} T_{5}$

$\mathrm{T}_{5} \mathrm{O}_{1}$

$\mathrm{C}_{4} \mathrm{C}_{2}$

$\mathrm{C}_{2} \mathrm{C}_{3}$ (b)

\section{After IV phenytoin}

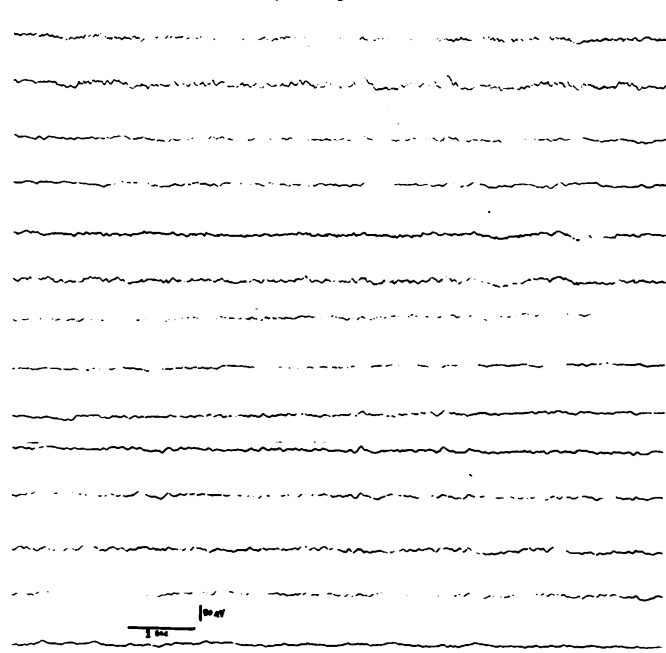

Fig 2 (a) The EEG of Case 3 showing left sided PLEDS during catatonic state. (b) Repeat EEG after intravenous phenytoin showing mild diffuse slowing. 
had a generalised tonic/clonic seizure with focal onset in the left arm after abdominal surgery for lysis of adhesions. He subsequently remained seizure-free despite non-compliance with phenytoin. On admission the patient appeared awake but with a flat affect and episodes of speech arrest. Muscle tone was increased and he maintained his extremities indefinitely in any passively placed bizarre posture. He responded to intense painful stimulation with facial grimacing but was unable to follow any simple commands. When pulled out of a chair he was able to walk unguided along the hallway with a rigid posture. An EEG shortly after admission showed periodic lateralising epileptiform discharges in the left parieto-temporal region (fig 2A). After the patient received 1 gram of phenytoin intravenously, a repeat EEG showed mild diffuse slowing (fig 2B) with complete resolution of catatonia. His other laboratory studies showed hypokalaemia, hypoalbuminaemia and abnormal liver function. A CT scan of the head showed mild diffuse cortical atrophy. The CSF was normal.

\section{Discussion}

Non-convulsive status epilepticus has many unusual manifestations. ${ }^{6}$ Although the level of consciousness in patients with this condition may vary from mild lethargy to severe clouding, the most common manifestation reported is a confusional state. ${ }^{78}$ Such patients often exhibit an expressionless facies, are immobile and uncommunicative, and respond poorly to painful stimulation despite a superficial awareness of their surroundings. At times, rhythmic twitching of the eyelids, lips or face can occur. Less commonly, these patients may also present with simple and complex automatisms, ${ }^{4-12}$ apraxia of movement, ${ }^{9}$ visual and auditory psychosensory symptoms, ${ }^{13}$ myoclonic movements, ${ }^{14-16}$ catatonia, ${ }^{3}$ focal neurological signs ${ }^{1214}$ and Ganzer syndrome. ${ }^{17}$ As variable as the clinical presentations may be, the EEG can manifest different degrees of bilateral epileptiform discharges with only rarely reported focal onset. ${ }^{12} 14$

The paucity of speech, expressionless facies, and the withdrawn state seen in patients with nonconvulsive status can easily mislead a clinician to consider a psychiatric aetiology for the patient's symptoms. Transient psychosis unaccompanied by clinically observable seizure activity in association with continuous epileptiform discharges on the EEG may also occur. ${ }^{16} 18$ Despite the similarity of the clinical manifestations, the EEGs in our patients showed three separate patterns: (1) generalised periodic and pseudoperiodic discharges (2) continuous right fronto-central spikes and sharp waves (3) left parietotemporal periodic lateralising epileptiform discharges. Catatonia in association with such discharges has not been described in the literature which we reviewed. ${ }^{19-21}$ The dramatic response to phenytoin in our three patients would indicate that the events were probably the result of cortical epilepsy with secondary generalisation to the limbic system rather than primary generalised status epilepticus.

Ballenger $e t a l^{8}$ studied the clinical features, ictal manifestations, and EEG phenomena in eight patients with complex partial status epilepticus. Three patients presented mainly with impairment of consciousness with no motor phenomenon, whereas five patients had confusion, aphasia, focal motor activity, and automatisms. Data from 17 previously studied cases of partial complex status epilepticus were reviewed by the same authors and found to have similar ictal manifestations. In none of these 25 patients was catatonia found to be an ictal manifestation. ${ }^{8}$ Although there are some earlier reports of catatonia as a seizure phenomenon, either the clinical descriptions were incomplete or the EEG correlation was lacking. ${ }^{45}$ Only one series described epileptogenic activity on EEG concurrent with the catatonic state. ${ }^{3}$

The importance of EEG in the diagnosis of patients with unusual behaviour manifestations cannot be over-emphasised. Without the EEG, these patients are often thought to have functional disorders. ${ }^{35}$ This paper emphasises that catatonia can be a manifestation of non-convulsive status epilepticus. One must also consider other various organic aetiologies 2 for catatonia, before resorting to the use of neuroleptic drugs or ECT in the treatment of this syndrome. Early EEG screening should be considered in any patient with sudden onset of unexplained bizarre behaviour, particularly catatonia, regardless of the "classical" nature of the observed phenomenon.

\section{References}

${ }^{1}$ Kahlbaum K. Catatonia. Baltimore: Johns Hopkins University Press, 1973.

${ }^{2}$ Gelenberg AJ. The catatonic syndrome. Lancet 1976; 1:1339-41.

${ }^{3}$ Thompson SW, Greenhouse AH. Petit mal status in adults. Ann Intern Med 1968;68:1271-9.

${ }^{4}$ Goldensohn ES, Gold AP. Prolonged behavioral disturbances as ictal phenomena. Neurology (Minneap) 1960;10:1-9.

${ }^{5}$ Gomez EA, Comstock BS, Rosario A. Organic versus functional etiology in catatonia: case report. J Clin Psychiatry 1982;43:200-1.

${ }^{6}$ Hauser WA. Status epilepticus: Frequency, etiology and neurological sequelae. In: Delgado-Escueta AV, Wasterlain CG, Treiman DM, Porter RJ, eds. Advances in Neurology. New York: Raven Press, 1983;34:3-14.

${ }^{7}$ Andermann F, Robo JP. Absence status: A reappraisal following review of thirty-eight patients. Epilepsia 1972;13:177-87.

${ }^{8}$ Ballenger CE III, King DW, Gallagher BB. Partial complex status epilepticus. Neurology (Cleveland) 1983;33:1545-52.

${ }^{9}$ Ellis JM, Lee SI. Acute prolonged confusion in later life as 
an ictal state. Epilepsia 1978;19:119-28.

${ }^{10}$ Vizioli R, Magliocco E. A case of prolonged petit mal seizures. Electrocephalogr Clin Neurophysiol 1953;5:439-40.

${ }^{11}$ Schwab RS. A case of status epilepticus in petit mal. Electrocephalogr Clin Neurophysiol 1953;5:441-2.

${ }^{12}$ Niedermeyer E, Fineyre F, Riley T, Uematsu S. Absence status (petit mal status) with focal characteristics. Arch Neurol 1979;36:417-21.

${ }^{13}$ Guinena YH, Taher Y. Psychosensory seizures "visual and auditory" of primary subcortical origin. Electrocephalogr Clin Neurophysiol 1955;7:425.

14 Bauer G, Aicher F, Mayr U. Nonconvulsive status epilepticus following generalized tonic/clonic seizures. Eur Neurol 1982;21:411-9.

15 Tucker WM, Forster FM. Petit mal epilepsy occurring in status. Arch Neurol Psychiatr 1950;645:823.

${ }^{16}$ Lennox WG, Davis JP. Clinical correlation of the fast and 